\title{
What's the Big Deal?
}

How Researchers Are Navigating Changes to Journal Access

Danielle Cooper

Oya Y. Rieger 


\section{ITHAKA S+R}

Ithaka $\mathrm{S}+\mathrm{R}$ provides research and strategic guidance to help the academic and cultural communities serve the public good and navigate economic, demographic, and technological change. Ithaka $\mathrm{S}+\mathrm{R}$ is part of ITHAKA, a not-for-profit organization that works to advance and preserve knowledge and to improve teaching and learning through the use of digital technologies. Artstor, JSTOR, and Portico are also part of ITHAKA.

Copyright 2021 ITHAKA. This work is licensed under a Creative Commons Attribution 4.0 International License. To view a copy of the license, please see https://creativecommons.org/licenses/by/4.0/.

ITHAKA is interested in disseminating this brief as widely as possible. Please contact us with any questions about using the report: research@ithaka.org. 


\section{Table of Contents}

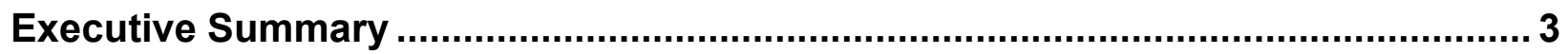

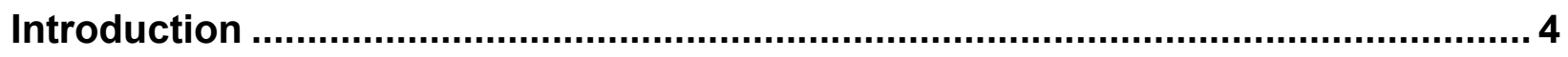

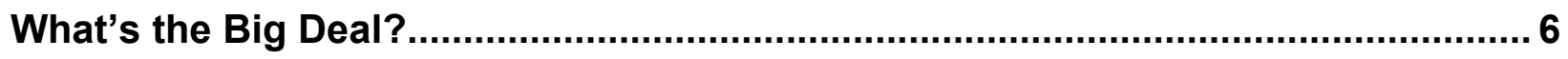

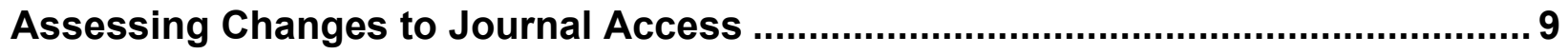

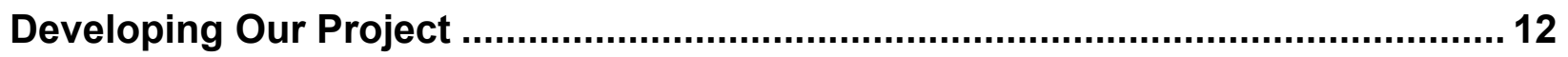

Project Findings

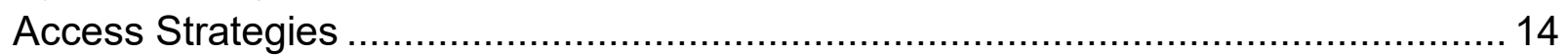

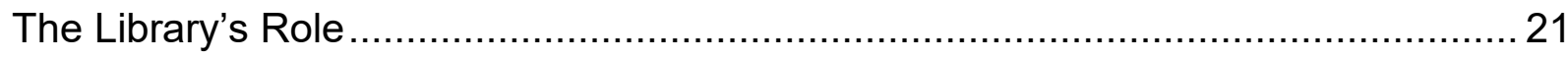

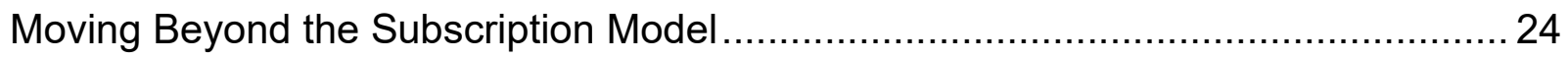

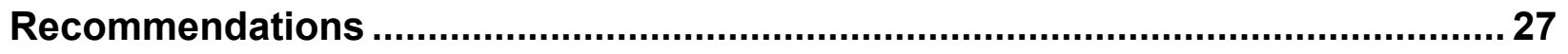

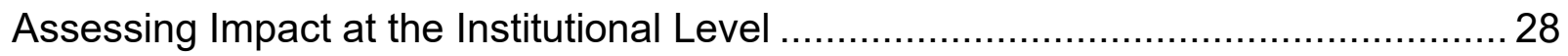

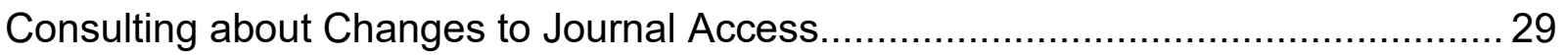

Navigating Shifts in the Library's Value Proposition............................................. 30

Appendix A: Partnering Schools and Their Contributors....................................... 33

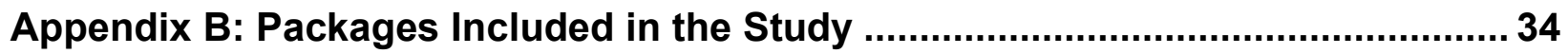

Appendix C: Interview Sampling Methodology ...................................................... 35

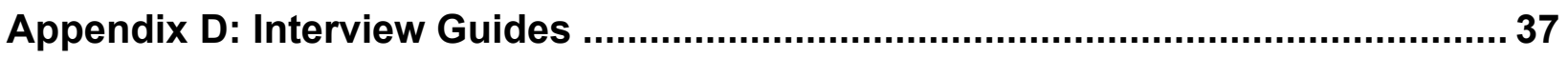

Interview Guide: Inquiring prior to a change to journal access.............................. 37

Interview Guide: Inquiring after a change to journal access.................................. 40 


\section{Executive Summary}

The dominant mode by which research libraries have provided maximum journal access as cheaply as possible-subscription bundles or "Big Deals"-is giving way to new approaches. This transition is taking place through a combination of negotiations, activism, business modeling, user needs research, and decision support, among other factors. To support these processes, Ithaka S+R partnered with 11 academic libraries to understand researcher perceptions to help inform their ongoing strategic decision making about Big Deal journal subscriptions.

Recognizing that libraries must also undertake case-by-case assessments prior to making decisions about any particular journal package, in this report we share findings from the project that merit wider public consideration. We detail patterns in how researchers approach discovery and access to journal content, focusing on their experiences when mechanisms for access change. These experiences are used as a jumping off point to also explore researchers' perceptions of the various models for facilitating their access to journal content and of the stakeholders engaged in that work.

We found that when a suite of journals is no longer available through a Big Deal subscription package, researchers experience little negative impact in the short term. There are some institutional, disciplinary, and career-stage variations, but overall researchers are able to work around the access barriers they encounter. This reality is deceptively benign. Researchers remain supportive of their libraries and are also interested in broader efforts to challenge the status quo of the scholarly communications business. However, they do not have a solid understanding of the strategies for advancing new modes of journal access beyond the subscription model, nor are they clear on what the library can and should provide in response.

We recommend three areas of activity that institutions should be especially mindful of when considering changes to journal subscription packages:

Create new mechanisms for assessing the impact of lost access to journal subscriptions. Many of the ways that scholars access journal content cannot be easily tracked by libraries, and it is not common for libraries to assess the effects of lost access over time. Should libraries take into consideration the inconvenience of lost access, even if cancellation is not an outright impediment to research?

Library consultative processes work and can be even better leveraged. The strategies for engaging researchers in decision-making processes around journal subscriptions are effective, and there is an opportunity to build on those further. Researchers appreciate transparency about how their library's decisions relate to the opportunities to change the scholarly communications ecosystem.

Libraries need to do more to navigate the shift in value proposition that comes with the loss of Big Deal journal packages. Researchers still equate the library's value with the extent to which it facilitates seamless access to journal content. By and large, 
researchers do not understand how any particular deal that confers new open access privileges for a set of authors at a specific institution represents an improved level of library value creation.

\section{Introduction}

This project comes at a critical juncture for how the journal subscription bundles that make up the majority of library collections expenditures, or "Big Deals," are positioned in terms of their value. ${ }^{1}$ In the past, the sheer size of a permanent collection could serve as a proxy for the prestige of a library, and by extension, the institution. In that context, bundled access to journals through a subscription provided an efficient way for libraries to achieve broad coverage for their patrons. But rising journal prices coupled with budgetary pressures within higher education are rebalancing this value equation, as are changing expectations about how scholarly work and outputs from research should be shared and disseminated. Digital piracy is also disrupting the status quo by facilitating the distribution of copyrighted content without permission. Amidst this backdrop, large research libraries are exploring how to unbundle their Big Deals and/or shift to new arrangements with publishers that prioritize open access.

The deals that libraries enter into with publishers have been a major determinant in how the institution supports its researchers as readers and authors. Libraries have established approaches for taking researchers' needs into account when making subscription decisions, but it is incredibly difficult for any individual institution to assess their current options in the context of what is ultimately a global transition. In response to this, in 2020 Ithaka $\mathrm{S}+\mathrm{R}$ partnered with 11 academic libraries to understand how evolving researcher approaches to accessing journal content should inform their journal licensing strategies. The cohort faced a variety of scenarios by which their researchers were potentially losing access to journals, through the cancellation of a Big Deal or stalled negotiation with a publisher. By convening a cohort with a variety of licensing scenarios we were able to collect evidence on when and how researcher experiences with journal access cut across local contexts, while still considering what that means for an institution's individual decision-making process on-the-ground.

The project was designed first and foremost to collect evidence for the participants' internal institutional purposes. In the process, we identified a number of insights that are also valuable for public consideration. Overall, we found that Big Deal cancellations do not translate into major changes for researchers day-to-day in the short term. ${ }^{2}$ Researchers are actively working around access barriers and are concerned about the inconvenience that comes with loss of subscription access, especially in the long term. They continue to find the version of record to be valuable, and the library's value continues to be framed through its ability to support reader access to that content type. Researchers are generally supportive of efforts to challenge the status quo of the scholarly communications business but are also uncertain about whether the

\footnotetext{
${ }^{1}$ The authors are deeply grateful to Joseph Esposito, Gwen Evans, Lisa Janicke Hinchliffe, and Roger Schonfeld for their comments on a draft of this issue brief. Any errors or omissions remain our own.

${ }^{2}$ Throughout this paper we refer to changes in access as Big Deal cancellations. In some cases, however, the Big Deals were not cancelled, but researchers lost access to licensed packages during prolonged negotiations.
} 
strategies that their libraries can take will bolster this. They question the extent to which any individual library or institution can be effective when acting independently in this arena.

Researchers, university administrators, and those working with libraries and other research support units on campus all have a stake in how their institutions shape their approach to fostering scholarly communications. While we designed the project for a specific set of institutions to learn from their researchers and each other when considering their licensing terms, we anticipate that the insight shared from that project will be of interest to other stakeholders engaged with scholarly communications including funders, government policy makers, and publishers.

Our recommendations focus on the main issues and strategies that individual institutions should consider in light of researchers' support needs. These recommendations are designed to serve as a complement to the targeted assessments that institutions must undertake when evaluating specific journal packages. Most notably, we found that the established strategies libraries employ to engage researchers in decision making related to bundled subscription packages is overwhelmingly successful. However, as the details from the researchers' accounts reveal, these findings are not necessarily a cause for celebration. Our findings point to a much deeper challenge facing universities than can be solved through any one library intervention: When researchers lose access through their institution to journals, the value of their institutional affiliation diminishes.

\section{A Note on Reading this Report}

We anticipate that this report will be of interest to multiple audiences-librarians, higher education senior leaders, publishers, funders, policy makers-concurrently with the recognition that some sections may be of greater interest to some audiences more than others.

What's The Big Deal? is a general overview of the Big Deal, its position in the scholarly communications ecosystem, and how library strategy has evolved with its emergence, growth, and decline. Those who are well-versed on the Big Deal's history may prefer to skip ahead.

Assessing Changes to Journal Access outlines the strategies and methodologies developed to evaluate Big Deal packages, which provides helpful context for how we designed our study. We anticipate that those with a professional interest in how vendor offerings are evaluated may find this section to be especially of interest even though they also may have the strongest background on this topic.

Developing Our Project details our process for designing and implementing the study. We anticipate that this section will be of interest to all readers regardless of their background.

The Project Findings examine researchers' experiences working with scholarly content when confronting Big Deal cancellations and their perspectives on the open access business landscape that is emerging from the Big Deal's wake. Each of the main finding areas begins with framing 
content in italics that is intended for a non-specialist audience. We anticipate that those who are short on time may choose to selectively read sub-sections of greatest interest to them.

In Recommendations we synthesize what can be learned from the project findings and use that evidence to point to three areas of activity that institutions should be especially mindful of when considering changes to Big Deal subscription packages, including cancellations. We anticipate that this section will be of interest to all readers regardless of their background.

\section{What's the Big Deal?}

For nearly two decades, a number of academic libraries have licensed a great deal of their journal content in the form of large bundles from each of the major publishers. These bundles, commonly known as "Big Deals," seized on the low marginal cost of digital distribution and the huge economies of operating at scale to transform the marketplace for scholarly and especially scientific communication. Typically first priced at a comparatively marginal increment over libraries' existing print subscription spend, Big Deals dramatically expanded access to journal content, making the entire output of a given publisher, rather than a subset of published titles, available across all institution types from small liberal arts colleges to the largest research universities. The tradeoff was that publishers achieved greater market power and locked in revenue streams in a sector already experiencing what some termed a "serials crisis." 3 The opportunity to strengthen market power and to lower allocated operating costs was so substantial that the Big Deal drove the logic behind several major mergers and acquisitions, leading to further market consolidation. ${ }^{4}$ When the Big Deal emerged, members of the library community and independent publishers foresaw its potential deleterious effects-namely diminishing the library's role as a collector, which by extension would lead to diluting library collections with titles researchers did not need and accelerating the library's dependence on a diminishing share of increasingly powerful publishers. ${ }^{5}$ Nevertheless, the opportunity to improve content availability and simplify acquisitions processes was compelling for many institutions, and indeed small institutions were suddenly able to provide a level of research support previously out of reach. ${ }^{6}$ The Big Deal firmly took hold.

While expanded content access was compelling, the Big Deal began to show limitations, including many of which were foreseen. Some publishers initially seized on their market power, and the expanded value these bundles provided, to raise prices at a rate that was simply incompatible with the slower pace of growth (in many instances decline) of library materials budgets. Academic libraries typically spend one third of their budgets on subscription purchases

\footnotetext{
${ }^{3}$ Aaron S. Edlin and Daniel L. Rubinfeld, "Exclusion or Efficient Pricing? The "Big Deal" Bundling of Academic Journals," Antitrust Law Journal 72, no. 1 (2004): 119-57, http://www.jstor.org/stable/40843619.

${ }^{4}$ Kenneth Frazier, "The Librarians' Dilemma: Contemplating the Costs of the 'Big Deal,"' D-Lib Magazine 7, no. 3 (March 2001), http://www.dlib.org/dlib/march01/frazier/03frazier.html.

${ }^{5}$ See for example, Mary M. Case, Joan Giesecke, and Kenneth Frazier, Implications of Aggregate Subscriptions to Electronic Journals, Birmingham, Ala: EBSCO Subscription Services Vantage Point (2001).

${ }^{6}$ Joseph Esposito, "Why Elsevier is a Library's Best Friend," The Scholarly Kitchen, January 9, 2018, https://scholarlykitchen.sspnet.org/2018/01/09/50692/.
} 
but that cost only represents about 0.5 percent of the university's budget overall. 7 Therefore, while some may argue that the Big Deal may actually be a good deal for the institution overall, it is still also an unsustainable deal for many libraries.

The concept of open access also challenges the logic of the Big Deal subscription model because it positions reading scholarly content as an important, indeed necessary, benefit to wider society, including members of the general public. Publishers give researchers the opportunity to make their articles open access by paying an article processing charge intended to offset the cost of that service, which puts the onus of open access on the researcher and the third parties willing to make funding available to them for this purpose. Large research libraries and funders have joined together, particularly in Europe, to call on publishers to "flip" their business models so that authors could be supported by their institutions to publish open access. Rather than charging libraries for access, these "transformative agreements," enable institutions to pay for their researchers' works to be made freely available online. From a financial perspective, they are arguably even "bigger deals" than Big Deals ever were for institutions. Institutional and cross-institutional bundled publishing services therefore still seem to have a future, but perhaps more for open access than subscriptions. Since January 2021 alone, some 87 transformative agreements have been reached, spanning institutions and consortia of at least 16 countries. ${ }^{8}$

While the value of bundled journal subscription packages have been under scrutiny for decades, the tactic of cancelling Big Deals outright in response has become much more common in recent years. 9 The strategic motivations for cancelling vary, with institutions especially in the US focusing their efforts on how to reduce their overall collections budget by unbundling, maximizing the use of open access content, and more fully leveraging interlibrary loan programs..$^{10}$ Other institutions, primarily in Europe, have negotiated new deals that align with their evolving open access policies, using cancellations as part of the negotiating strategy. This is resulting in (sometimes even bigger) transformative deals.

Regardless of the underlying strategic motivation, Big Deal cancellations lead to scholars losing access to current content through one of the main channels they may rely on, which is through their institutional subscriptions. For example, Elsevier's portfolio includes about 2,500 journal titles. When the University of California cancelled its Big Deal with Elsevier, that meant that going forward its researchers would continue to have access to about fifteen percent of newly published content from those titles, which represents what was already being made open access through those titles. In order to access new content beyond that, scholars would need to leverage

\footnotetext{
${ }^{7}$ See Kent Anderson's calculations in Lindsay McKenzie, "Are 'Big Deals' Actually Good Deals?" Inside Higher Ed, May 30, 2019, https://www.insidehighered.com/news/2019/05/30/questions-raised-over-true-burden-big-deal.

${ }^{8}$ ESAC Transformative Agreement Registry, https://esac-initiative.org/about/transformative-agreements/agreement-registry/.

${ }^{9}$ Kenneth Frazier, "What's the Big Deal?" The Serials Librarian 48, no. 1-2 (2005): 49-59; Cindy Sjoberg, "E-Journals and the Big Deal: A Review of the Literature," School of Information Student Research Journal 6, no. 2 (2017), https://doi.org/10.31979/25752499.060203.

${ }^{10}$ Casey Daniel Hoeve, "Resource Management in a Time of Fiscal Scarcity: Combining Qualitative and Quantitative Assessment for Journal Package Cancellations," The Serials Librarian 75, no.1-4:42-44, doi: 10.1080/0361526X.2019.1576571.
} 
interlibrary loan or more informal channels such as their peers. ${ }^{11}$ Scholars have never exclusively accessed content through their institutions, and the advent of file sharing multiplied the opportunities for access long ago. However, it is also important to recognize that scholars cannot equally rely on their peer networks or are comfortable engaging with other access backchannels, including those that are illegal. It is telling that the recent study assessing the changes (or seeming lack thereof) to German scholars' ability to cite Elsevier publications following loss of access to the full text, described informally sharing content between colleagues as "shadow libraries." 12 Given researchers' uneven abilities to leverage workarounds, it is perhaps understandable why the breadth of the library's holdings, including its subscription content, continues to serve as a proxy for the stature of said institution, including as a researcher recruitment tactic. ${ }^{13}$

In the case of institutions hoping to negotiate transformative deals, there is the risk that diminished access will drag on longer than anticipated if negotiations stall. At the University of California, for example, the lag between cancelling their Big Deal and securing a new Transformative Deal was a little more than two years, and for the Swedish library consortium Bibsam, the lag was approximately a year and a half. For institutions that do not pursue transformative agreements, a Big Deal cancellation also involves either a transition to a smaller subscription plan or an unbundled approach where titles are selected a la carte. ${ }^{14}$ Continued access to backfiles, or the journal content from earlier years which is generally made available separately as part of a collection, may help alleviate the effects of a cancellation. However, the research value of backfiles diminish over time especially in the sciences, and the platforms that publishers build out for users to access backfiles when a current subscription is no longer being maintained may not have the same affordances, which can further diminish its utility. At institutions that are cancelling outright this means that their users' access is being permanently altered.

Previously, library research on Big Deal cancellations has focused on the impact on those affiliated with a particular institution or system, typically to better inform negotiation

\footnotetext{
${ }^{11}$ Lindsay McKenzie, "UC Drops Elsevier," Inside Higher Ed, March 1, 2019, https://www.insidehighered.com/news/2019/03/01/university-california-cancels-deal-elsevier-after-months-negotiations; Lindsay McKenzie, "Big Deal for Open Access," Inside Higher Ed, March 17, 2021, https://www.insidehighered.com/news/2021/03/17/university-california-reaches-new-open-access-agreement-elsevier.

12 The term "shadow libraries" has previously been used to describe efforts to share scholarly content through backchannels at scale, such as Facebook groups or SciHub, see, John Karaganis (ed), Shadow Libraries: Access to Knowledge in Global Higher Education (MIT Press, 2018), but we take note that the metaphor is also being extended to researchers' personal "shadow libraries" of article downloads, as per Nicholas Fraser, Anne Hobert, Najko Jahn, Phillip Mayr, and Isabella Peters, "Deal: Investigating the Influence of Restricted Access to Elsevier Journals on German Researchers' Publishing and Citing Behaviours," May 25, 2021, https://arxiv.org/abs/2105.12078.

${ }^{13}$ Although not the focus of this study, it is also important to recognize that the breadth of a library's holdings can also serve as a proxy for other metrics research success, which can be complicated by lost access to Big Deal subscriptions. For example, a recent study on citation trends written by scholars affiliated with the University of California omitted articles from Elsevier in their dataset because they were not available to the authors at the time. See "Data Sources and Procedures," in Marta Serra-Garcia and Uri Gneezy, "Supplementary Materials for Nonreplicable Publications are Cited More than Replicable Ones," Science Advances 7, DOI: 10.1126/sciadv.abd1705.

${ }^{14}$ For analysis of trends in what libraries retain following a Big Deal cancellation see Lisa Janicke Hinchliffe, "What Do Libraries Keep When They Cancel the Big Deal," Scholarly Kitchen, July 14 2020, https://scholarlykitchen.sspnet.org/2020/07/14/what-dolibraries-keep-when-they-cancel-the-big-deal/.
} 
approaches and/or to determine which journals to retain when unbundling. Collective initiatives such as the Scholarly Publishing and Academic Resources Coalition (SPARC) and novel valuation tools such as Unsub and DeltaThink's Open Access Data and Analytics Tool help facilitate library strategic assessments as they explore the implications for their own user groups. ${ }^{15}$ Understandably, institutions must determine the extent to which and how they publicly share findings from these kinds of explorations based on the status of their negotiations.

Given the change to available access mechanisms to scholars, it is crucial for academic libraries, regardless of their motivation for cancelling, to have a shared understanding of how Big Deal cancellations affect users over time. This includes understanding scholars' evolving research and teaching strategies and their perceptions of the role their libraries should play in supporting that work.

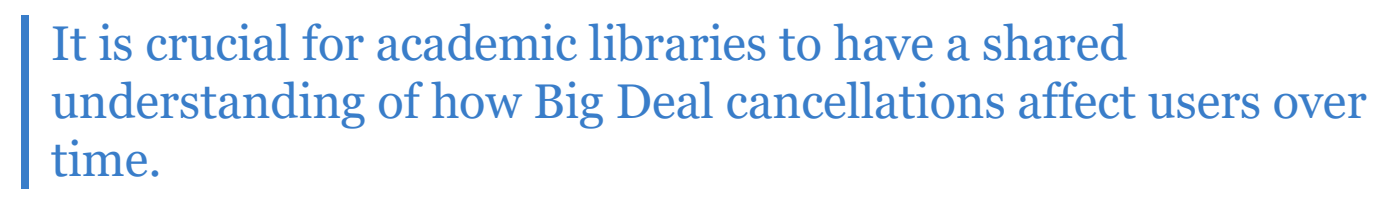

Our study is unique because it represents the first attempt by a group of libraries to come together to examine user perspectives on Big Deal cancellations across a variety of institutional and cancellation contexts concurrently. We did not intend for our project to replace the assessments individual libraries conduct to inform their cancellation approaches, but rather to serve as a complement by fostering a wider discourse on what institutions can learn from each other. The study included libraries that were in the process of considering a particular cancellation alongside those who have already made cancellation decisions. Through our study, we sought to gather qualitative insights from the researchers most likely to be impacted by losing access to a particular package due to their research interests, rather than through a more general survey of scholars regardless of their disciplinary orientation.

\section{Assessing Changes to Journal Access}

In recent years, as libraries considered whether to cancel their Big Deals, they have used a number of evaluation methods, largely quantitative, to assess those deals' value. ${ }^{16}$ When the goal is simply to reduce cost by reducing the number of subscription bundles or titles within the bundle, mitigating the disruption that lost access may cause to researchers is often the primary

\footnotetext{
${ }^{15}$ For more on SPARC see https://sparcopen.org/who-we-are/; for more on Unsub see https://unsub.org/; for more on DeltaThink's Open Access Data and Analytics Tool see https://deltathink.com/open-access/oa-data-analytics-tool/.

${ }^{16}$ Marc-Andre Simard, Jason Priem, Heather Piwowar, "The Aftermath of Big Deal Cancellations and Their Impact on Interlibrary Loans," September 9, 2020, https://arxiv.org/abs/2009.04287.
} 
aim of such assessments. ${ }^{17}$ These assessments include measuring article downloads, and overlap analysis, as well as other bibliometric data and input from subject specialists. ${ }^{18}$

Particular attention has been given to calculating return on investment, anchored by cost-peruse calculations. These approaches are complicated by the nuances of usage statistics. For example, newer titles with smaller backfiles inherently have a higher cost-per-use because there has been less time for users to access these resources and less content for them to access overall. However, providing access to newer titles is important to fostering a diverse and growing scholarly communications ecosystem. Determining how much of a paywalled journal's content is made available through open access is an increasingly important factor in decision-making. ${ }^{19}$ And because many libraries continue to have perpetual access to journal backfiles post cancellation, it is also important to understand the extent to which, and for how long, less current content is valuable to researchers, including how that varies from field to field. ${ }^{20}$

In addition to gathering usage data, the library's decision-making process also involves seeking input from relevant stakeholders such as subject librarians and faculty members to identify journal titles that should be selected on an a la carte basis due to their importance to users. ${ }^{21}$ While gathering input from researchers before or during a negotiation process is common, collecting data following a cancellation is rarer. Most notably, the Swedish library consortium Bibsam conducted a path breaking study of users and e-resource managers in 2019 on the effects of lost access to journals on their users when negotiations with Elsevier stalled in 2018. The study featured two surveys, one focusing on users' strategies for accessing content, their attitudes about the cancellation, and their perceptions of Elsevier; the second survey focused on the effects of the cancellation on administrative capacity at each institution and plans for reallocating funds. ${ }^{22}$ About half of respondents reported that the cancellation negatively affected their work, but overall respondents found it difficult to take a position on the cancellation strategy because they lacked background knowledge about the work of libraries and their institutions in this area. ${ }^{23}$

\footnotetext{
${ }^{17}$ Lea Currie and Marcia Lee, "Beyond Usage Data: Taking the Deep Data Dive," The Serials Librarian 74 (2018), DOI: 10.1080/0361526X.2018.1428027.

${ }^{18}$ Cindy Sjoberg, "E-Journals and the Big Deal: a Review of the Literature," The Student Research Journal 6, no. 2 (2017), https://doi.org/10.31979/2575-2499.060203.

${ }^{19}$ Kristin Antelman, "Leveraging the Growth of Open Access in Library Collection Decision Making," in At the Helm: Leading Transformation, ACRL (2017), https://resolver.caltech.edu/CaltechAUTHORS:20180329-154012961; Lisa Janicke Hichliffe, "Are Library Subscriptions Over-Utilized?" The Scholarly Kitchen, May 22, 2018, https://scholarlykitchen.sspnet.org/2018/05/22/arelibrary-subscriptions-overutilized/.

${ }^{20}$ Heather Piwowar, Jason Priem, and Richard Orr, "The Future of OA: A Large-Scale Analysis Projecting Open Access Publication and Readership," bioRxiv, Oct. 9, 2019, https://doi.org/10.1101/795310.

${ }^{21}$ Stéphanie Gagnon, “Journal Publishers' Big Deals: Are They Worth It?” Against the Grain 29:2 (2017), DOI: 10.77711/2380176X.7747; Beatriz Betancourt Hardy, Martha C. Zimmerman, and Laura A. Hanscom, "Cutting Without Cursing: A Successful Cancellation Project," The Serials Librarian 71, no. 2 (2016): 112-120.

${ }^{22}$ Lisa Olsson, Camila Hertil Lindelöw, FridaJakobsson, and Lovisa Österlund, "Open Access Consequences of Sweden Cancelling Elsevier," June 28, 2019, https://zenodo.org/record/3259809\#.YG3IA-hKjIU.

${ }^{23}$ Lisa Olsson, Camilla Lindelöw, Lovisa Österlund, and Frida Jakobsson, "Swedish Researchers' Responses to the Cancellation of the Big Deal with Elsevier," UKSG Insights, November 11, 2020, https://insights.uksg.org/articles/10.1629/uksg.521/.
} 
Given the complexity of internal and external variables that need to be taken into consideration, it can be quite demanding for any individual institution or consortia to study post-cancellation effects comprehensively over time. A further layer of complexity is that a change to a journal's access model today will also affect tomorrow's researchers. But when confronting these decisions, we tend to focus on what they will mean for today's researchers because envisioning the future is far less straightforward. It is hard to predict how the profile of an institutions' research community will evolve because it is dependent on institutional research priorities and trends in how research is conducted that are often not yet apparent.

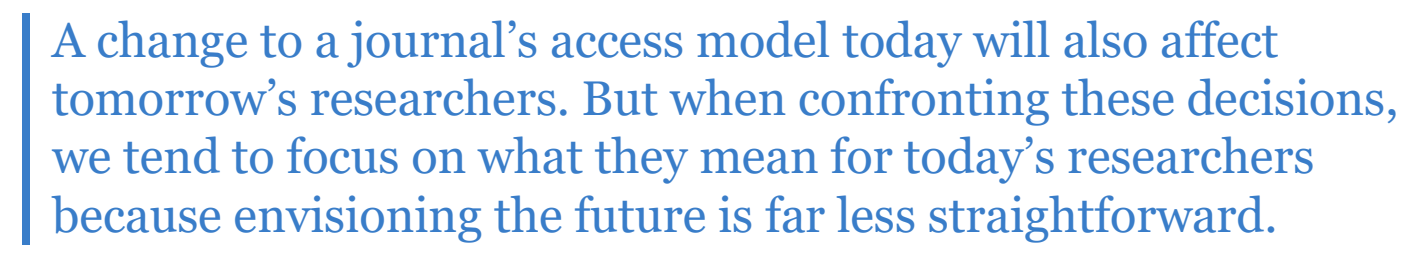

It is also understandable that libraries may choose to conduct some internal research on user experience following a significant shift in journal access and that some or none of the research outcomes can be publicly shared in the interest of ongoing or future negotiations. For example, the University of California shared that it ran a brief poll to assess the impact of its stalled negotiations with Elsevier on its community after access had been lost to new ScienceDirect content for six months. ${ }^{24}$ The University of California made some of the findings of that poll subsequently available, such as through a conference keynote by Mackenzie Smith and a summary document posted online. ${ }^{25}$

Bibsam and the University of California ultimately reached transformative deals with Elsevier that fully restored users' access to content, but there are institutions who have or are considering cancellation where reaching such deals will not be possible. Many institutions, especially those that cancelled Big Deals as a cost saving measure, simply do not have the resources or capacity to track the effects of cancellations on their users.

While the motivations and strategies of libraries cancelling Big Deals vary based on local cultures and practices, by developing a project where libraries could come together to learn about the effects of their cancellations on users, we aimed to mitigate the assessment challenges

\footnotetext{
24 "After Talks with Elsevier Stalled, the University of California Has Been Working to Advance Open Access. Here's How," Berkeley Library, January 23, 2020, https://news.lib.berkeley.edu/oa-update.

${ }^{25}$ Similar to the findings from the Bibsam study, the University of California's survey identified fields that were more or less likely to be impacted by the loss of access. Scholars most affected by the loss of access—such as those in the health sciences-were the least supportive of the strategic position. The University of California shared that 44 percent of respondents reported that the loss of access had some impact on their research and 39 percent also reported strongly supporting its position. These findings were used by the University of California to conclude that the inconvenience to researchers should not outweigh a desire to cancel, which was also argued as being bolstered by earlier research conducted at the University of California-Berkeley that found broader support for open access among faculty members, see MacKenzie Smith, "Moving to Open," Keynote Address, RLUK, March 23, 2021, https://www.youtube.com/watch?v=RIfXPan5Zd0; "UC Poll on Impact of Loss of Access to Current Elsevier Articles via ScienceDirect," https://www.library.ucsb.edu/sites/default/files/elsevier poll summary.pdf; Chan Li, "Taking the Temperature on Open Access Among UC Berkeley Faculty," Ithaka S+R, November 12, 2019, https://sr.ithaka.org/blog/taking-the-temperature-onopen-access-among-uc-berkeley-facultyl.
} 
for individual libraries and contribute a form of evidence of broad value to the community. We hope that in doing so we can also encourage further collective research, ideally conducted with users who have experienced cancellations over a longer time scale.

\section{Developing Our Project}

Ithaka $\mathrm{S}+\mathrm{R}$ partnered with 11 academic libraries in order to examine the commonalities and differences in researcher experience when facing significant shifts to journal access through their institutional affiliation. We intentionally partnered with universities contemplating different shifts in access to journal content, including which vendors the content is provided by, whether they were considering cancelling a Big Deal, or whether they had recently lost access due to a planned cancellation or stalled negotiation. The cohort's guiding research questions included:

- How do significant shifts to journal access, such as Big Deal cancellations, affect the research experiences of users and their perceptions of the library?

- What are users' strategies when their access to journal content changes?

- How do libraries project, assess, and monitor the potential impact of changes to what journal content they help to make available, such as through Big Deal cancellations?

Our approach to creating a cohort of partnering universities was to assemble a "coalition of the willing," meaning that we opened participation to any school that was considering or had recently cancelled a Big Deal, and we issued an open call for participants alongside targeted invitations to institutions known to have compelling cancellation contexts. ${ }^{26}$ The cohort and Ithaka S+R were the sole sponsors of the project in order to ensure that the insight would be as pertinent as possible for internal decision-making purposes.

We greatly appreciate the contributions and engagement from our partnering schools: Florida State University, Freie Universität Berlin, Ohio University, Pennsylvania State University, University at Buffalo, University of Denver, University of Kansas, University of Oklahoma, University of Pittsburgh, University of Wyoming, and Wesleyan University. Appendix A lists the contributors from each partnering school. Within the cohort, there was roughly even representation of institutions exploring the effects of a possible change to available journal content versus those exploring the effects of a recent loss in available journal content. Appendix B outlines which package each school evaluated.

Our inclusive and more broadly ranging approach to the inquiry therefore responds to the reality that there are a variety of reasons why institutions are shifting away from their Big Deals and that the priorities relating to journal subscription strategies shift over time. For example, consider the differences between Freie Universität Berlin and the University Buffalo, both of which interviewed researchers about their experiences following the cancellation of an Elsevier

\footnotetext{
${ }^{26}$ Danielle Cooper and Oya Y. Rieger, "Project Announcement: Cancelling the Big Deal," Ithaka S+R, March 4, 2020, https://sr.ithaka.org/blog/project-announcement-cancelling-the-big-deal/.
} 
package. At Freie Universität Berlin, researchers' access to the three largest commercial publishers of scholarly content (Elsevier, Wiley, and Springer) is mediated through ProjektDeal, which is organized at the national level and mandated to negotiate for transformative deals that make publications immediately available as open access in lieu of individual authors paying an article processing charge ${ }^{27}$ Negotiations between Elsevier and ProjektDeal stalled, which led Freie Universität Berlin to pull out of its deal at the end of 2017. As a result, its researchers do not have access to new ScienceDirect content from 2018 onwards. In contrast, after a year and a half of negotiation, the University of Buffalo's researchers regained access to Elsevier in April 2020. At the University of Buffalo, access to Elsevier is mediated at the state level through the SUNY system, which transitioned in 2020 from its Big Deal to a smaller package of "core titles." The contract also includes a ten percent discount for SUNY-affiliated authors on article processing charges to make content open access through Elsevier journals. ${ }^{28}$

At the outset of our project, each partnering library identified a journal package of strategic priority to their library and then undertook a systematic assessment in order to identify two departments that were 1) highly likely to be affected by an existing or potential loss of access to that package's content, 2) strategic to the library's interests, ${ }^{29}$ and 3) appropriate for study given the research methodology. Using a semi-structured interview guide developed by Ithaka S+R, the libraries then conducted interviews with seven to 12 researchers from the selected departments to understand their discovery and access strategies, opinions about alternative modes of publishing, and perceptions of their library's role in providing access.

Recognizing that skills, experiences, and levels of access to journal content available through institutional affiliation vary over the course of a research career, we chose to focus this study on tenure track professors as opposed to students or contract faculty. ${ }^{30}$ Additional research with a focus on graduate students will be valuable to further expand our understanding of perceptions and behavior when navigating shifts to journal content made available through institutional affiliation. Graduate students not only are at a crucial skills development phase but also may have different reading habits, and they play an important role in supporting faculty in conducting research.

Ithaka $\mathrm{S}+\mathrm{R}$ analyzed the 89 interviews by coding them in NVivo qualitative data analysis software using a grounded theory approach. We identified a sample of 41 interviews for the initial exploratory phase of the analysis, 19 from schools considering a potential shift in access and 22 from schools that had already experienced a shift in access. The sample was carefully designed to be proportionally representative of the total body of transcripts produced across the cohort by institution, departmental affiliation, and rank. We then conducted a targeted analysis

\footnotetext{
${ }^{27}$ For more information on ProjektDeal see: https://www.projekt-deal.de/about-deal/.

${ }^{28}$ For more information about the results of SUNY's current deal with Elsevier, see Denise Wolff, "SUNY Negotiates New Deal with Elsevier," University of Buffalo Now, April 21, 2020, http://www.buffalo.edu/ubnow/briefs/2020/04/suny-elsevier-deal.html.

${ }^{29}$ For example, to bolster library priorities to support new programs or units, or to update library priorities given program/unit phaseouts.

${ }^{30}$ Freie Universität Berlin's sample also included some faculty that are officially classified as postdoctoral researchers because they are more closely equivalent to assistant professors. Those interviews were categorized accordingly in Appendix C.
} 
of the entire dataset on priority themes identified from that initial phase. Appendix C outlines the sampling approach and Appendix D reproduces the interview guides for reference.

\section{Project Findings}

\section{Access Strategies}

When assessing the value of a Big Deal package, a central issue is whether the cancellation will lead to a substantial change to researchers' ability to access the scholarly content they rely on. More and more content is being made available through open access, and there are a variety of ways that scholars can access content that is otherwise behind a paywall, including through their institution (e.g. interlibrary loan, special request for purchase), immediate collegial networks (e.g. directly emailing the author or another peer), or broader networks or platforms (e.g. quasilegal academic social networks, illegal sharing sites). They can also choose to work with an earlier version of the content (preprints) or find alternative content altogether.

This study explored the potential consequences of diminished journal access on scholars' research and teaching processes and examined the mix of access strategies they employ in response. Understanding how researchers conceptualize their own access experiences within the evolving scholarly communications ecosystem is essential for probing the relationship between institutional choices and the effects to individual researchers and their broader networks.

\section{Making Do}

A Big Deal cancellation represents a significant shift in what journal content is available through institutional subscription, but it is much more complicated to understand how this affects the individual researcher day-to-day. Our study therefore involved carefully selecting interviewees who were most likely to experience this impact due to the overlap between their disciplinary affiliation and the journal content in the Big Deal package. Among those who were interviewed after such a cancellation had taken place, we found that they did not generally report a significant impact to their research. They also shared a widespread perspective that the cancellation had minimal to no impact on their reputation or that of their department or institution. Within our project the cancellations had all been fairly recent, which suggests there is relatively little effect to researchers, or institutional reputation, within the immediate one-totwo-year time span following a cancellation.

Typically, researchers considered the cancellation a "loss to efficiency amounting to inconvenience" as opposed to an insurmountable obstacle. As one interviewee explained, "it's added extra steps to getting access to papers that come up...I keep finding journals that I would, you know, access occasionally, but I can't anymore.” Researchers demonstrated a general understanding of alternative access approaches. For example, one researcher noted that "losing access doesn't mean losing access anymore...you can still get the article. You just can't get it immediately." Some respondents could point to very specific groups within their department that were disproportionately affected and/or specific titles that were no longer available. 
Explaining that there was no problem in accessing major high impact journals, an interviewee did note an issue with more specialized titles, "It's when you need things specific to your discipline that I've noticed a drop off." Only occasionally, there were comments indicating recognition of frustrations, such as "It didn't really impact me...but I'm not a volcanologist but the volcanologists were mad."

While the access strategies were largely similar among all interviewees in the study, the perceptions of a cancellation's relative impact to their work did vary somewhat more between those who were interviewed about a potential cancellation and those who had experienced a cancellation. Those who had not yet experienced a cancellation were more likely to frame the perceived effects less concretely and also more negatively. This suggests that it can be difficult for researchers to realistically anticipate the effect of a specific cancellation to their research. It also suggests that at the outset the possibility of change can be perceived as an outsized threat, and by extension, needs to be managed carefully.

Researchers also acknowledged that they anticipated that the loss of access would be increasingly problematic over time as the backfiles they still have access to age. As one interviewee observed, "right now, there's only five or so months [with] publications that we don't have access to...And frankly, I suspect, some people haven't even noticed it...but it's going to get bad." There was also the open question as to when the bottom would fall out in terms of maximum impact and how that would relate to the critical saturation point of widely available open access content to ameliorate the effects of any given subscription cancellation. Projecting that the "amount of trouble will gradually increase over time, approaching some maximum amount of trouble," one researcher explained," I don't think I wouldn't describe it as ever running out of content, I would just sort of describe this, you know, placing increasing burden on the process of finding the content."

Others pointed to the difficulty of libraries concretely assessing impacts given the variety of workarounds researchers are now employing. One scholar's creative approach to remedying this situation especially highlights the difficulties here: "My New Year's resolution this year was, if I got anything off of SciHub...I went ahead and then requested it through the library loan...the university's supposed to be making decisions on the basis of what we're doing, and when we bypass all these things, we're messing with that."

These perspectives reflect that there are possible long-term implications for cancellations and that given the relatively early point that most institutions are in, it will be important to track this issue over time. Researchers were especially mindful of affects to their collegial networks. As one interviewee observed, "I have colleagues who have lost their access to Elsevier, and then what they do is they write to other people, 'can you send me this PDF?'... that doesn't seem like a solution." What was less common among the interviews were reflections about how relying on colleagues can also mean relying on their colleague's institution to pay for subscription access, and further probing on this issue may be worthwhile for future study. 


\section{When to Pursue the Version of Record}

Researchers in our study who had already experienced a shift in institutional access to journal content reported being relatively unaffected because of their ability to "make do" with other access strategies available-but what does that actually entail on the ground? Researchers in the study consistently described that their decision making for pursuing the full-text version of a paywalled article hinged on the time horizon relative to their deadline, the availability of substitute content, and whether the abstract sufficed. If they determine that they do in fact need a specific article and confirm that they cannot find an open access version on the web, they generally prefer to contact a colleague or author(s) or use interlibrary loan (discussed in further detail below) over illegal channels like SciHub (except in the case of interviewees from Freie Universität Berlin, discussed in further detail below).

While the majority of interviewees reported a willingness to make do with content still available through subscriptions and by pursuing legal alternative access mechanisms, some scholars noted the appeal of more mercenary approaches to ensure continuing access to the version of record. It was rare for interviewees to report securing a personal subscription for themselves or their lab, but more notably, while some noted they are boycotting serving as reviewers for publishers due to the problematics of their business models, others acknowledged how serving as a reviewer is a useful tactic for gaining access to publications following a cancellation. "I often have access to ScienceDirect because I'm reviewing a lot...most of the journals are with Elsevier that I'm looking into. And I mostly have access because I'm reviewing one paper a month," described an interviewee. Another related remark was, "I know of other people who are younger and do not review so much. But when they review, they save the 30 days [of] access until they need it really." $3^{1}$ Others expressed interest in more of these kinds of arrangements being created by publishers, such as being provided with some form of free access in exchange for choosing to publish with a specific title (e.g. "if these journals did give me a free article, I'd go to them every single time.") Similarly, some pointed to their frustration that this rewards system-granting free access in exchange for providing labor to journals, such as serving on the editorial boardisn't already the norm. As one interviewee explained, "it feels pretty harsh to be an associate editor and to get hardly any payback for that," noting that there was an email in his inbox from Springer about his access privileges because he is an editor. These responses, while not in the majority, still suggest that the value proposition of publishing is evolving, with the necessityand desirability - of access to the version of record as a form of compensation for editing and reviewing labor becoming more common. It also resonates with broader debates around the relationship between incentive structures and mechanisms for ensuring the integrity of peer review processes.

\footnotetext{
${ }^{31}$ Elsevier provides complimentary 30-day access to ScienceDirect and Scopus through "Reviewer Hub" to scholars who review a single article. The reviewer has the latitude to determine when the 30-day access commences. More information on the program here: José Stoop, "Introducing Reviewer Hub: Showcasing our New Reviewer Engagement Platform," December 11, 2020, https://www.elsevier.com/connect/reviewers-update/introducing-reviewer-hub.
} 


\section{The value proposition of publishing is evolving, with the necessity-and desirability - of access to the version of record as compensation for editing and reviewing labor becoming more common.}

\section{When to Go Beyond the Version of Record}

Working with earlier versions of the content, or preprints, is another way that researchers can potentially ameliorate reliance on articles stuck behind paywalls. "Preprints" are versions of academic articles before they have gone through formal peer review and publication. Some researchers make preprints of their work available through online repositories, such as their institutional repository, or websites like ResearchGate. Some noteworthy fields have deeply established cultures for sharing preprints, where there is a strong value in sharing research and seeking feedback from a broader researcher community prior to formal publication. Leveraging preprints to disrupt current business models in scholarly publishing centered on the version of record requires a broader swath of researchers to rely on preprints for a wider array of uses. Tracking evolving perceptions and use of preprints is therefore important for those who are considering the potential disruptions of significant shifts in institutional access that can be caused by Big Deal subscription cancellations.

When asked about their use of preprints in research or teaching, the interviewees in this study displayed clear patterns in what they perceived as their utility and how that related to the utility of the version of record. The interviewees reported that they prefer not to use preprints for most teaching purposes due to difficulty for students in understanding the context of a preprint. As one interviewee explained, "I generally discourage preprints in the students' term papers...and one of the reasons it's hard enough to get them to really grasp the purpose of citations and references." This quote highlights how interviewees anticipated that preprints add an extra level of complexity to the already challenging process of introducing students to the scholarly communications ecosystem. With the need to assign a limited number of articles that correspond to specific pedagogical aims, instructors therefore generally prefer to opt for those that they perceive as the easiest to navigate as a novice reader, which are peer reviewed and published in respectable journals.

Springer Nature recently conducted a survey in collaboration with ResearchGate which examined their authors' perception of the version of record. $3^{2}$ Although we recognize that Springer Nature and ResearchGate are not independent researcher organizations, we nevertheless observed some noteworthy resonances with the findings from our own study. Similar to our interviewees, the survey respondents highlighted how preprints can be more or less acceptable for certain tasks. For their own use, particularly when it is for quickly browsing, Springer Nature authors reported that preprint usage is acceptable. For more formal

\footnotetext{
32 Mithu Lucraft, Katie Allin, and Imogen Batt, "Exploring Researcher Preference for the Version of Record," figshare, February 17, 2021, https://doi.org/10.6084/m9.figshare.13834532.v1. For a helpful reflection on the findings of the Springer Nature/Resarch Gate study and ongoing discourse on the value of the VOR see Lisa Janicke Hinchliffe, "Publishers Care about the Version of Record, Do Researchers?" April 5, 2021, The Scholarly Kitchen, https://scholarlykitchen.sspnet.org/2021/04/05/publishers-care-about-theversion-of-record-do-researchers/.
} 
applications, such as which version of an article gets cited in a publication, these authors noted that citing the published article is preferable due to its perceived trustworthiness. Our research adds to this picture by highlighting how the version of record is also preferable in teaching because it puts less onus on the reader to understand the nuance of the peer review process. Given that students are at an earlier point of experience with evaluating scholarly literature, the version of record was seen by our interviewees as the easier format for them to navigate. 33

It is important to recognize that preprints can be as difficult for some researchers to contextualize as it is for their students. Some scholars who did not come from fields with an established preprint culture also expressed confusion as to how to engage with preprints meaningfully. One interviewee remarked, "I don't quite fully understand what's going on with those and how they'll change once they get accepted and if that matters how they change...I don't know what the implications are for publishing if you put it on one of these servers beforehand.” In fields where preprint practices are less established, interviewees frequently questioned their quality and expressed their ongoing commitment to the peer review process. There was also confusion among this group as to how a preprint relates to or can be linked to the version of record. 34

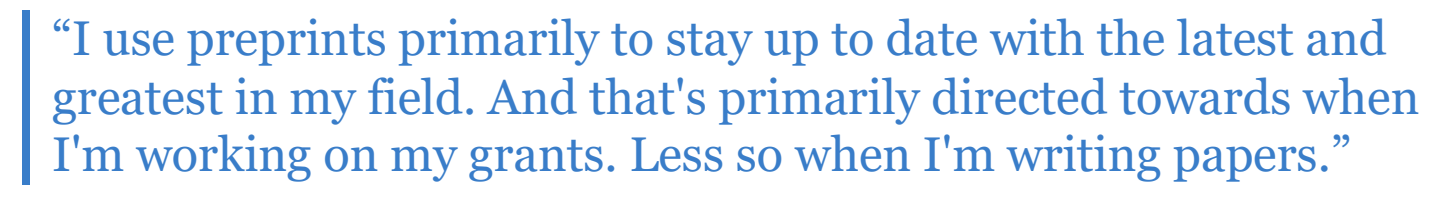

Echoing the findings from the Springer Nature study, interviewees from fields where preprint adoption is stronger emphasized how they fit into a larger ecosystem of scholarly communication including more traditional publishing outputs. As one interviewee explained, "I use preprints [referring to bioRxiv] primarily to stay up to date with the latest and greatest in my field. And that's primarily directed towards when I'm working on my grants. Less so when I'm writing papers."

\section{Using Interlibrary Loan Sparingly}

Requesting content through interlibrary loan is one way researchers can secure paywalled articles that their institutions do not subscribe to. Indeed, investing in and promoting use of interlibrary loan is a major strategy that libraries take to alleviate the potential loss of access. And yet a number of studies demonstrate that Big Deal cancellations do not correspond to a great increase in interlibrary loan usage. 35 We observed a similar phenomenon-researchers

\footnotetext{
${ }^{33}$ In contrast, in the information science fields, this kind of barrier is also framed as an opportunity to teach information literacy to students, even at an introductory level. See for example Sarah Hare and Cara Evanson's approach to using paywalls as an opportunity to teach the concept of information privilege to undergraduate students, "Information Privilege Outreach for Undergraduate Students," CR\&L 79, no. 5 (2018), https://crl.acrl.org/index.php/crl/article/view/16767/18993.

${ }^{34}$ CrossRef, for example, enables members to link their preprints to the version of record through DOls, see https://www.crossref.org/community/preprints/.

${ }^{35}$ See for example: Kristin Calvert, Rachel Fleming, and Katherine Hill, "Impact of Journal Cancellations on Interlibrary Loan Demand," Serials Review 39, no. 3 (2013): 184-187, https://doi.org/10.1080/00987913.2013.10766391; Wayne A. Pedersen, Janet Arcand, and Mark Forbis, "The Big Deal, Interlibrary Loan, and Building the User-Centered Journal Collection: A Case Study," Serials Review 40, no. 4 (2014): 242-250, https://doi.org/10.1080/ 00987913.2014.975650; Jonathan Nabe and David C.
} 
who had lost access reported that this did not lead to them using interlibrary loan more frequently.

The choice to not rely more frequently on interlibrary loan is reflected in perceptions that many interviewees reported about these programs. While those who had used interlibrary loan had generally positive things to say, respondents more typically focused on the perceived delays as a barrier to use. This is noteworthy considering the number of offerings that speed up and streamline this service, such as Reprints Desk, Copyright Clearance Center's Get It Now, and ExLibris' RapidILL tool. As one researcher indicated, “interlibrary loan yeah, you can't have immediate access to it ... I think that's why this kind of move on to the next article is more frequently in my head because I don't want to wait."

Even those who spoke positively about their library's interlibrary loan service typically reported viewing this as a process requiring some additional effort for them and also for the library. This additional effort meant that they considered whether it is absolutely necessary to consult a specific article and explored other access avenues before making an interlibrary loan request. As one interviewee shared, "if it's an article I really want and need, I'll put in a request through the Library website, I do that maybe in like ten percent of the cases, because usually there's a wait. And by the time I get the article, I've often forgotten why I needed it." The perspectives from this study suggest that even as libraries work to expand, speed up, and streamline their interlibrary loan services, interlibrary loan cannot supplant other approaches to pursuing content when researchers hit a paywall, including simply moving on if an alternative source can be found more immediately.

\section{The SciHub Horizon}

When researchers hit a paywall, they may then look for alternative avenues to secure the version of record, such as by reaching out to their network, engaging with a social media channel to facilitate sharing, or explore an illegal sharing platform, most notably SciHub. SciHub is especially challenging for libraries because its great utility for many researchers makes it impossible to ignore, but its aggressively illegal approach also makes it challenging to formally factor into strategic planning. With SciHub's halting new content uploads as of January 1, 2021 in response to ongoing litigation in the High Court of New Delhi, and Virgin Media blocking access to SciHub in the United Kingdom, come important reminders that readers who rely on illegal channels for access are dependent on uncertain systems. ${ }^{36}$ It is precisely because of its volatility to researchers that SciHub was identified as warranting exploration for this study.

Fowler, "Leaving the "Big Deal" ... Five Years Later," The Serials Librarian 69, no. 1 (2015): 20-28, https://doi.org/10.1080/0361526X.2015.1048037; Kristin Calvert and Whitney Jordan, "Closing the Loop on Collections Review," Serials Review 46, no. 3 (2020): 209-214; Jacob L. Nash and Karen R. McElfresh, "A Journal Cancellation Survey and Resulting Impact on Interlibrary Loan," Journal of the Medical Library Association: JMLA 104, no. 4 (2016): 296; Steven A. Knowlton, Iulia Kristanciuk, and Matthew J. Jabaily, "Spilling Out of the Funnel: How Reliance Upon Interlibrary Loan Affects Access to Information," Library Resources \& Technical Services 59, no. 1 (2015): 4-12; Marc-Andre Simard, Jason Priem, and Heather Piwowar, "The Aftermath of Big Deal Cancellations and Their Impact on Interlibrary Loans," arXiv preprint: 2009.04287 (2020).

${ }^{36}$ For more on the SciHub litigation in the Court of New Delhi, see the court filing, December 24, 2020, http://delhihighcourt.nic.in/dhcqrydisp 0.asp?pn=258223\&yr=2020; for more on Virgin Media's blocking SciHub, see "List of Court 
Data collection for this study involved faculty being interviewed by librarians, and it is therefore important to recognize that some interviewees may not have been comfortable fully admitting the extent to which they engage with illegal channels to procure content. However, it is also noteworthy that a number of interviewees openly expressed confusion over the relative legality of different sharing mechanisms with their interviewers, including the difference between sharing directly with colleagues versus through posts to social networking platforms, and how seemingly more social forms of sharing relate to accessing content through platforms like SciHub, which are explicitly designed to facilitate piracy.

Uniquely among the cohort, researchers from Freie Universität Berlin did report a more frequent reliance on SciHub. Recognizing that our study was relatively small scale, we still found it noteworthy that a little more than half of the researchers from Freie Universität Berlin use SciHub when they encounter problems accessing a paywalled journal. Moreover, roughly a quarter of those who do not use SciHub admitted asking a colleague to use it or to otherwise download and share a journal illegally. Our findings therefore resonate with studies showing relatively high concentrations of SciHub users throughout Europe. 37

By comparison, few interviewees from US institutions in our study admitted to using SciHub, and many reported that they had never heard of the site. However, some interviewees who were not previously aware of SciHub took the opportunity to express that they were not opposed to the concept in theory. As one US researcher who had never used Sci-Hub commented, because the website "offers easy access to information that should be accessible for [the] public," she could "see both sides of the argument." Another US researcher, when informed that Sci-Hub contains pirated journal articles, was more direct, saying: "I've got to write this down ... Now I'll do this website too. Cool." Conversely, virtually all researchers at Freie Universität Berlin had firsthand knowledge of SciHub, and the few who did not described using other informal strategies to circumvent paywalls, such as by reaching out to their peer networks.

Across the cohort, those who reported using SciHub shared how resorting to the platform is a matter of expediency, driven partly by a lack of institutional resources, but also by a need to avoid cumbersome access methods and interfaces. As one researcher explained, of all access mechanisms, "Sci-Hub is just the most convenient." When exploring alternative access mechanisms becomes too cumbersome, the likelihood that some researchers will use SciHub increases substantially. This raises the question of whether researchers from different disciplines, perhaps operating under different time constraints, are more or less likely to gravitate towards Sci-Hub. By serving conveniently as a "one-stop shop" for freely available content, Sci-Hub is also ultimately creating a fairly widespread "legion" of users. ${ }^{3}$

\footnotetext{
Orders Pursuant to Which Virgin Media is Required to Block Access to Identified Websites," https://www.virginmedia.com/help/listof-court-orders.

${ }^{37}$ John Bohannon, "Who's Downloading Pirated Papers? Everyone," Science, April 28, 2016, https://www.sciencemag.org/news/2016/04/whos-downloading-pirated-papers-everyone.

${ }^{38}$ Rick Anderson, "They Know We Know They Know: Does Sci-Hub Affect Library Subscriptions? The Scholarly Kitchen, July 3 , 2019, https://scholarlykitchen.sspnet.org/2019/07/03/they-know-we-know-they-know-does-sci-hub-affect-library-subscriptions/.
} 
And yet, interviewees' responses also suggest that SciHub use is not only determined by institutional access or expediency, but by an interviewee's group or ideological orientation. For example, we observed that researchers from US institutions, regardless as to whether they had recently experienced a significant shift in access to subscription content, were not more or less likely to use Sci-Hub. This remained true even for those who sympathized with researchers who did use Sci-Hub.39 Regional or ideological factors may be driving the different use patterns in Europe and the US.

\section{The Library's Role}

A core component of the academic library's mission is to ensure that affiliated researchers can discover and access the content they need, and at one point in time the Big Deal subscription package represented a cost-effective way to meet those goals at a much greater scale. But as a larger and larger portion of their budgets goes toward subscribing to scholarly journals, it has proven difficult for many libraries to balance out providing content to researchers and their fiscal responsibility to the institution. With the majority of researchers continuing to perceive the library's value through its provision of content, it is important to understand how their perceptions of the library's role shift as access to subscription content changes and how the library steers those changes with its users. $4^{\circ}$ It is also important to understand how shifts in access relate to another major pillar of library support-the discovery of content.

In conjunction with understanding researchers' evolving perception of the library's role in supporting their discovery and access, this study also probed how this related to researchers' perceptions of their institutions. There are a myriad of ways for supporting access beyond the publisher subscription model, but ongoing questions as to how and to what extent libraries and their institutions should be involved in fostering those other models remain. Understanding scholars' perspectives on this issue also illustrates what they see as the library's role in the wider scholarly communications ecosystem.

\section{Discovery Happens Elsewhere}

This study provided an opportunity to compare the discovery experiences of researchers who had experienced a major shift in the content made available to them through institutional subscription to those who would be potentially facing such a shift in the near future. Given that libraries continue to invest both space and resources in providing an array of digital discovery tools, it is also important to understand the relationship between researchers' experiences

\footnotetext{
${ }^{39}$ Significantly, US researchers account for 17.8 percent of all peer-reviewed science and engineering articles published between 2006 and 2016, whereas Germany accounts for just 4.5 percent. See "Outputs of S\&E Research: Publications," in Science \& Engineering Indicators 2018, National Science Board, January 2018,

https://www.nsf.gov/statistics/2018/nsb20181/report/sections/academic-research-and-development/outputs-of-s-e-researchpublications. Given the prestige of publishing in these journals and the stake US researchers have in them, it is only natural that a higher proportion of US scholars would be reluctant to completely abandon the existing publishing model—even when they lacked access to those journals. Moreover, the relatively high volume of journal publications by US researchers may also reflect a higher proportion of editor labor, which quite often serves as a kind of quid quo pro for journal access.

40 Melissa Blankstein and Christine Wolff-Eisenberg, "Ithaka S+R US Faculty Survey 2018," Ithaka S+R, April 12, 2019, https://sr.ithaka.org/publications/2018-us-faculty-survey/.
} 
finding and accessing content, including when they face a shift in how they can access content. And yet, it may not seem intuitive to consider this relationship because the role of libraries in facilitating discovery is diminishing. ${ }^{41}$ This is reflected both in the popularity of Google Scholar as a discovery platform and through the availability of plugins, like the Open Access Button, which enable researchers to identify relevant content accessible to them without relying on their library website. ${ }^{42}$

The findings from this study continue to confirm that using library discovery portals as a gateway for accessing subscription content is not tethering researchers to the library website. As one interviewee summarized, "I do not find myself using library specific search tools for articles as often as I maybe did back in the day...the connected nature between social media and online search engines and the publication releases of various journal outlets do a pretty good job for me." The diminished role of the library as a locus of discovery underscores the library's weakening ability to intervene in the scholars' workflow, and by extension, its lessening influence on how sources are delivered.

Our findings suggest that following a substantial shift in access researchers do not need to adjust their discovery strategies accordingly. This is because the majority of researchers, including those we interviewed who were contemplating a potential change to their access, have already shifted from relying on the library website to using other platforms and features that make access to content as seamless as possible, including content still requiring their institutional credentials. Google Scholar was the most common starting point, whether the interviewees were looking for a specific/known article, trying to stay current by following new works, or conducting literature reviews. This is consistent with industry-wide findings and what we have observed in the Ithaka $\mathrm{S}+\mathrm{R}$ triennial faculty survey. ${ }^{43}$ Interviewees also noted that they sometimes consult subject-specific platforms to supplement their search, and the platforms they invoked reflect the disciplinary coverage of the Big Deal packages considered in the study.

In the relatively rare instances when scholars cited using the library catalog, it was typically within the context of looking for a known monograph or a journal article. In other cases, they brought up the library catalog to highlight the difficulty in using it, including confusion about how to transition from discovering to accessing articles remotely, finding discovery too convoluted (too many buttons to click to find the article they need), and finding that link resolvers are not that dependable, causing frustration with broken links. These weaknesses have been known for many years, and the fact that so little progress has been made on these issues should be a major cause of concern for the academic library community.

\footnotetext{
${ }^{41}$ Roger C. Schonfeld, "Does Discovery Still Happen in the Library? Roles and Strategies for a Shifting Reality," Ithaka S+R, September 24, 2014, https://sr.ithaka.org/blog/does-discovery-still-happen-in-the-library-roles-and-strategies-for-a-shifting-reality/. 


\section{Effectively Stewarding the Cancellation}

In order to help mitigate the potential effects of a cancellation to their research, interviewees at institutions considering a cancellation identified a variety of preferred strategies their libraries could take in conjunction with their planning. These suggestions overlapped strongly with the tactics interviewees who had already experienced a cancellation reported appreciating. These suggestions also resonated with best practices surfaced in the literature. 44 The interviewees emphasized the importance of a variety of communication approaches to ensure maximum coverage as opposed to simply emailing. They stressed the importance of discussions that allow bi-directional feedback through town hall meetings, departmental meetings, and meetings with liaison librarians. Their comments indicated that they value seeing data on access trends and cost and benefit analyses, as well as completing surveys and co-reviewing lists of titles proposed for cancellation. As one interviewee expressed, "so much research went into figuring out how to spend less money in a way that had the smallest amount of impact for faculty...And that you guys were using a lot of time and energy [to resolve the problem."

Interviewees also appreciated how consultation and evidence gathering processes lead to greater awareness and transparency of how the political economy of scholarly communications relates to financial decision making at their institution. Interviewees at institutions where a cancellation had already taken place generally communicated that they understood the context and rationale for the cancellation. When asked if the cancellation affected their perception of the library, the response was uniformly "no," and often was coupled with sympathetic perspectives of the constrained environment the library is making decisions within. As one interviewee highlighted, "the library is looking after researchers by being good stewards of the resources that exist at the university." Similarly, another interviewee noted, "I sympathize with your position....it has reminded me of how tight the budget must be.”

This position is also complicated by the reality that many interviewees in the study still ascribed some value to the library, and by extension its institution, based on the degree to which it can provide access to scholarly materials. One scholar noted that at "a research university the library is arguably the most important thing” and journal access should be as convenient as possible. Another researcher remarked, "I used to think our library was great and now I think it's okay...a good library has things that are difficult to find." Along the same lines, one scholar commented, "I used to be able to tell people, well, we have the best library, one way or the other, we can get anything we want and that's not true anymore."

\section{The Role of the Institution vs. the Role of the Library}

Researchers interviewed for this study more commonly expressed disillusionment over how resources are allocated and priced within the institution, the higher education sector, and the business proposition of scholarly communications. Some interviewees especially reflected on

\footnotetext{
${ }^{44}$ See for example Jaclyn MacClean, Diane (DeDe) Dawson, and Charlene Sorenson, "Communication Collections Cancellations to Campus: A Qualitative Study," College and Research Libraries 82, no. 1 (2021), https://crl.acrl.org/index.php/crl/article/view/24751/32587; Brittany O'Neill and Rebecca Kelley, "Delivering Bad News: Crisis Communication Methods in Academic Libraries," College \& Research Libraries 82, no. 4 (2021), https://digitalcommons.Isu.edu/cgi/viewcontent.cgi?article=1090\&context=libraries pubs.
} 
spending priorities at their institution. As one shared, "I was really mad. I see all the things that get money, the way money is spent on this campus. And then to have research resources be what gets cut is really offensive." Others focused more on what they perceive as the problems with the business of scholarly communications more broadly, such as "It is academia, you know, all of this information is being generated on mostly tax funds, right? And now the journals, the publishers are in some cases making it really expensive to get at our own information." Accuracy about how public funding relates to scholarly publishing aside, what is also noteworthy about this position is how it reflects a strong perception among interviewees, regardless of geography, that the university research enterprise is ultimately in the jurisdiction of the public, and by extension, that its mission is best served by making access to research findings free to all.

\section{"I was really mad. I see all the things that get money, the way money is spent on this campus. And then to have research resources be what gets cut is really offensive."}

There was also uncertainty among interviewees about the end game of cancellation strategies, both at their institutions and more widely. Some reflected on the limited utility of cancellation as a tactic in and of itself without some other end goal for the institution (e.g. renegotiating the Big Deal or pursuing a new transformative arrangement). Others questioned the utility of cancellation as a mechanism unless institutions across systems and countries can work together effectively as a bloc. As one interviewee expressed, "if it's a whole country like Germany or France or a whole country saying, 'we're not going to buy your product,' then they're [publishers] much more likely to actually negotiate, as compared to [our institution] saying we don't want your product anymore." In this context, the library's stance as an advocate was considered valuable by some. For example, one interviewee reflected, "I have only positive feelings for the library here. And like I said, I'd even have more pride if you guys periodically took a stand and canceled something on those grounds [of advocating for systemic change within scholarly publishing]. I think that's good, too. The whole system has to change.”

\section{Moving Beyond the Subscription Model}

The value of the Big Deal subscription is intimately connected to the relative availability of open content, and debates continue as to how this content should be made available and who should shoulder the costs. 45 While it is widely recognized that the value of the Big Deal is in decline, publishers can still argue that there is at least some value to subscriptions given the ongoing unevenness of open access coverage and the lack of leadership from other sectors in effectively making open content available.

It is important to understand scholars' perspectives on open access business approaches that seek to move beyond the current subscription-based models sold to institutions. We asked researchers about their perspectives on some of the open access models that are being advanced.

\footnotetext{
${ }^{45}$ For a helpful primer on Open Access publishing models see, Lisa Janicke Hinchliffe, "Seeking Sustainability: Publishing Models for an Open Age," The Scholarly Kitchen, April 7, 2020, https://scholarlykitchen.sspnet.org/2020/04/07/seeking-sustainabilitypublishing-models-for-an-open-access-agel.
} 
They expressed frustration and general confusion over publisher business models and questioned the efficacy of their institutional interventions-covering article processing charges or creating institutional repositories-in this space. They had some ideas about who they would prefer to advance the business of scholarly publishing including open access, namely societies, with very limited understanding of how such a model would actually work.

\section{Frustrations with Article Processing Charges}

Interviewees had the greatest familiarity with making articles open access by paying an article processing charge to publishers. They especially emphasized the challenges of covering these costs as they try and also make the best use of limited funds. One interviewee observed, "[the article processing charge to make the article available through open access] effectively is an undergrad field assistant for the entire summer. So I can pay for open access or I can train an undergrad student and my job is to train students."

\section{"I can pay for open access or I can train an undergrad student and my job is to train students."}

Another response illustrated the complexity of the decision-making process when researchers must factor the cost of open access to them as authors against the benefit to others as readers. For instance, one researcher described, "I hope that in my own small way, I am working towards a more equitable society. I do my best to publish open access, but that comes at a cost, a literal cost. Like I can't fund a grad student for a summer kind of cost, and funding grad students who come from very diverse backgrounds is also really important for a more equitable society, so I feel like I'm asked to rob Peter to pay Paul."

Interviewees also voiced concerns for how article processing charges can be a barrier to other researchers, such as those from institutions with limited resources or from fields with relatively less grant funding available to cover article processing charges. They reflected on the differences among post-docs, graduate students, and senior and junior faculty as each group has different financial abilities and different levels of pressure to publish. Putting the onus on the author to cover more costs also means that they may have to negotiate with publishers, which can lead to further inequities in pricing systems. Some interviewees reported finding themselves negotiating and trying to find workarounds to avoid high fees: "And it's my understanding that right now, during COVID, journals are swinging all kinds of deals and you can just flat out say I don't have \$2000, I've got this much, you want it?” These concerns are important to reflect on as the prevalence of article processing charges continues to grow with the maturation of the open access market. 46

Interviewees also highlighted how homespun institutional initiatives to help cover the costs of article processing charges have an uneven and at times problematic effect. Some scholars were unclear as to when or why a library would pay article processing charges versus some other

\footnotetext{
${ }^{46}$ Dan Pollack and Ann Michael, "Open Access Charges - Consolidation, Increases, and Breaking Through the \$10K Barrier," DeltaThink, March 8, 2021, https://deltathink.com/news-views-open-access-charges-consolidation-increases-and-breaking-throughthe-10k-barrier/.
} 
institutional unit, or whether it is an intrusion into academic freedom to have institutions involved at all. It was not uncommon to hear comments especially about the futility of such programs, for example: "I guess the libraries have some grants for open access publications. But my understanding has been that that's very limited. And everyone in my department who's applied to get them has been told that they're too late, and it's already been used, and they don't have any more money."

\section{Questioning the "Business" of Open Access}

The interviewees for this project generally claimed to favor open access but also consistently raised questions about sustainability issues and were unclear about the long-term vision for leveraging open access to transform the status quo of scholarly communication. Their questions reflect calls to carefully attend to how open access is being leveraged as a business model by publishers and the reality that "in the pursuit of open science, open access is not enough." 47 After praising "the spirit of open access," one of the researchers interviewed was quick to follow that "the open access model is simply a way for the publishers to make more money." Another interviewee stressed that "it should be free to publish, and free to get it after it's done." Then, the researcher questioned, "But again, that's kind of simplistic because that costs money. And so where does that money come from?" There were questions about how the open access model is affecting the quality of scientific literature and if "open access is generating more journals" and if "it is getting more difficult to know where to publish things."

Trust and quality continue to be core values for many of the scholars interviewed. Some feel closer to their own research communities and networks. There were several references to the continuing value of society publishers (learned societies) as one researcher articulated, "I would prefer if the open source journals are managed by the...scientific societies...because they can have quality control over it." Some created a stark dichotomy between the societies and the commercial publishers, but of course many societies have relationships with major commercial publishers and those working closely with their societies with such configurations could reflect on the complexities of these relationships. As one interviewee explained, "I'm starting to become part of the leadership of my various societies and our societies have society journals. We['ve] got a little Elsevier issue.... what is our society going to do about our relationship with Elsevier and how much longer [are] we going to put up with the problems that we've had?’” Others also reflected on the reality that publishing is a business for societies too and recognized that the transition to open access must be particularly challenging to navigate. As one interviewee mused, "the economic model is a little hard for me to quite get my head around...that money model probably is drying up. If they are saying 'I'm going to produce these [articles] open source,' and I think they are, then they're trying to find the [new] money model, right?" Such comments indicate how researchers are trying to align and balance the potential benefits of moving to open access, with the business implications, and a perception that societies can be best trusted to keep scholars' interests at heart. Researchers are being confronted with these considerations in part because the business of scholarly publishing is transitioning from a

\footnotetext{
${ }^{47}$ Claudio Aspesi and Amy Brand, "In Pursuit of Open Science, Open Access Is Not Enough," Science 368, no. 6491 (2020): $574-$ 577, https://dspace.mit.edu/handle/1721.1/128966.
} 
"journal economy," to an "article economy," which the larger publishers can more easily capitalize on. In this period of transition, our findings also suggest that many researchers do not understand the extent to which societies are already working with vendors to facilitate their publishing processes.

\section{Open Access and Broadening Opportunities for Discovery}

When asked about their opinions on how the ability of other scholars to read their articles without a subscription might impact how their works are used and cited, most interviewees had not given this much thought. Some comments revealed that although they believed that open access indeed can increase readership, that was not their primary decision-making criteria. The comments indicated that they prefer to focus on finding the right publishing venue for their specialty and also consider who they want to reach out to (international audience vs. a specific research group). As one of the interviewers explained, "I try to publish my research where it fits the best or where it gets the most readers or the most readers which are interested in it. And so I try really to find places or find journals which are appropriate for the story that I want to tell."

Another way that researchers can leverage open access is by making versions of content available through green open access channels, such as by posting works on their institutional repositories. Although scholars were asked specifically about institutional repositories, they barely mentioned them in the context of considering which open access approaches were most promising for effectively disseminating scholarly content. The few comments focused on how they did not perceive their institutional repository as effective for discovery and access relative to other platforms designed for sharing content, including those that are not strictly considered open access. An example of this stance was, "I would say, for me, something like ResearchGate is preferable to an institutional repository, just because, like, I don't want to have to go to 100 different institutional repositories. And everyone can put their articles on ResearchGate, it's kind of like the agreed upon place to go for this kind of thing."

\section{Recommendations}

The study's findings shed light not only on the patterns of impact for researchers experiencing changes to journal access but also into the strategies for assessing that impact. The findings also point to how changes to journal access affect users' perceptions of their library, their institution, and the scholarly communications ecosystem more broadly. These perceptions are informative both for determining the communication and engagement approaches taken by libraries regarding subscriptions and for considering how libraries frame collecting strategies more broadly.

Below are our recommendations for some of the key ingredients individual institutions should consider when planning for changes to journal access. While it is beyond the scope of this study, we recognize that libraries need to conduct their own targeted assessment of the potential effects before proceeding with changes to any particular vendor license. 


\section{Assessing Impact at the Institutional Level}

The study's findings point to several areas of risk for libraries seeking to assess the impact of a potential or recent change to journal access. First, scholars' first-hand accounts have some utility in assessing impact, especially in helping to identify which groups within a discipline or department will be affected. But, these accounts must be coupled with other data points due to the challenges of concretely predicting the degree of potential impact, especially given the variation within a given department or disciplinary area (and based on career stage). The lack of consensus about how much negative impact is acceptable for a researcher to tolerate complicates these assessments further. Second, even with other data points, it is difficult to assess the impact of cancellations on access as scholars acclimate and get used to workarounds as a part of their usual research workflows. The findings from this study suggest that the current levels of access continue to be largely satisfactory, given the available resources at the individual university level and collectively among the institutions of scholars' peers and academic/social networks. The reliance on colleagues from other institutions to provide access informally still often involves relying on these colleagues' institutions paying subscription fees. Most notably, due to the huge volume of publishing and abundance of available literature, scholars do not seem constrained by not having access to any single article. However, locating items by contacting colleagues or authors, skipping or moving onto alternative sources, or pursuing other informal, and sometimes illegal channels are activities that cannot be captured by libraries in the same way as interlibrary loan requests.

Taken together, these two risks highlight how there is a larger strategic issue that libraries and their universities must face when considering making changes to how they facilitate journal access for scholars: the extent to which frictionless access is a priority area for supporting their affiliated researchers. A willingness to allow their researchers to experience at least some preventable friction and choosing not to track this friction is a choice that many institutions will continue to make.

\section{There is a larger strategic issue that libraries and their universities must face when considering cancellations: the extent to which frictionless access is a priority area.}

Recommendations for assessing cancellations:

- Take a nuanced approach to considering preprint use. Publishers are working to defend the value of the version of record by bringing preprints into their article submission workflows and linking them to their versions of record, so it is most important for libraries to continue to track this space. $4^{8}$ Preprint use is uneven and discipline dependent as there are only a handful of well-established services such as arXiv and bioRxiv. The interviewees consistently expressed their commitment to the peer review process and stressed the essential role editorial processes play in ensuring the quality and reliability of scientific information. They

\footnotetext{
${ }^{48}$ For more on the domestication of preprints see, Danielle Cooper, Oya Y. Rieger and Roger Schonfeld, "Can Publishers Maintain Control of the Scholarly Record?" The Scholarly Kitchen, January 6, 2021, https://scholarlykitchen.sspnet.org/2021/01/06/canpublishers-control-scholarly-record/.
} 
also continue to value the version of record and are often unsure about the status of papers found on different repositories.

- Develop a more effective mechanism for factoring in degrees of access friction into collective decision making. Antelman's proposal to adjust cost per download calculations for open access availability-and the development of the Unsub tool to automate that work-has been groundbreaking for the field. It is significantly more challenging to systematically calculate how much content in any given package is less formally available, including illegally, but even an exercise modelling some methodologies and very hypothetical scenarios would be of immense value to libraries. And given that loss of institutional access often leads to inconvenience without preventing researchers' ability to do their work outright, an exploration of how to factor in degrees of inconvenience ("friction") when seeking alternative access, would also be incredibly helpful for library decision making. However, assumptions that take into account the researchers' ability to informally solicit content from elsewhere may suggest a tacit support for at least some level of access inequality among researchers.

- Track the effects of loss of journal access holistically over time. In addition to assessment work undertaken prior to a significant change to journal access, it is important that the library consider projected trends in the evolution of their institution's research community (e.g. hiring priorities) and continue to assess the effects of that decision over time. Given that it is challenging to track when scholars access content outside the library, such as through interlibrary loan, these assessments should involve connecting with scholars directly about their evolving experiences, including through surveys, interviews, or focus groups. This strategy enables libraries to continue to refine their subscription strategies to meet the evolving needs of users and develop a deeper understanding of the impact of those decisions over time as their backfiles age and users' alternative access habits coalesce.

\section{Consulting about Changes to Journal Access}

The findings from this study are a powerful testimony to the efficacy of common library strategies for communicating and consulting with their users around changes to journal access. The interviewees who were asked to consider a potential change to journal access indicated preference for the strategies that those who had already experienced a change in journal access confirmed worked for them: using different communication methods (e.g., email, town hall discussions, individual consultations, reports, etc.) to share reasons behind the change in access (short- and long-term), lists of journal titles that could potentially be affected, usage data, and workaround strategies. Interviewees who had already experienced a change in journal access generally displayed understanding of the difficult budgetary decisions their libraries were making and trust in how their libraries were making those decisions.

Most interviewees had a general understanding of the ongoing tensions between academic libraries and large publishers over subscription fees but typically had less awareness of the broader trends in how journal access is provided. This suggests that libraries can further foster solidarity by using these processes to not only communicate about their own negotiations with publishers but also to build awareness of how their tactics relate to the work happening across 
the higher education sector. In contrast to attending general workshops on open access or the publishing ecology, actively contemplating the potential impact of changes to their own scholarship makes these broader issues more immediately relevant.

Recommendations for maximizing consultation processes:

- Have a robust plan. Communications and consultation are essential to managing stakeholder expectations effectively and this will ideally involve a variety of strategies deployed concurrently. This plan needs to be tailored to the unique context of the institution and its users.

- Adjust communication and consultation processes depending on the motivations for and desired end goal of the negotiation. A change to how an institution supports journal access may occur for a variety of reasons, such as budgetary pressures, low usage, or desire to dedicate funding to open access for authors. It can be difficult for scholars to parse out these distinctions, and they will benefit from consultation processes that clearly map out the stakes.

- Default to transparency. Users want to have a clear understanding of what is at stake and what the desired outcomes are. They want to know what evidence is being used to make a decision and appreciate the opportunity to actively contribute to the collection and review of that evidence.

- Use consultative processes to build broader support. Communication and consultation processes around changes to journal access are a good opportunity to educate users about library decision making. Leveraging these opportunities can lead to even more awareness of the strategies being taken by the library sector.

\section{Navigating Shifts in the Library's Value Proposition}

We are currently in an interim period where more and more institutions are unbundling Big Deals and there is not yet a clear path forward among competing open access business models. For example, Heather Piwowar and colleagues highlight the upward trend in Unpaywall users being able to avail themselves of open access versions of articles. However, they were most commonly able to do so through Bronze schemes, where articles are made free-to-read on the publisher website without an explicitly Open license, which means that the content may not remain open in the long term. ${ }^{49}$ Depending on the pace at which subscription-only packages are cancelled relative to content being made openly available, there may be an interim period with increasingly limited opportunities for scholars to leverage access through popular informal workarounds, such as asking colleagues in their direct network for help. The scholars in this study largely reported that they are not (yet) experiencing such a critical point of inflection. But they were also aware that there is no systematic coordination around cancellations on a global scale and wondered what the net effect would be if cancellations became too widespread too

\footnotetext{
${ }^{49}$ Heather Piwowar, Jason Priem, Vincent Larivière, Juan Pablo Alperin, Lisa Matthias, Bree Norlander, Ashley Farley, Jevin West, and Stefanie Haustein, "The State of OA: A Large-Scale Analysis of the Prevalence and Impact of Open Access Articles," PeerJ 6 (2018): e4375. https://peerj.com/articles/4375/.
} 
quickly, both on the efficacy of interlibrary loan and less formal routes for sharing among colleagues.

The findings from this study point to the strategies scholars are already taking in the absence of institutional access. This includes getting personal or lab subscriptions or securing access through quid pro quo arrangements with publishers who grant access in exchange for peer reviewing and editorial labor. This also includes going further and further beyond researchers' immediate networks, which will also be increasingly affected by cancellations, thereby necessitating the use of quasi-legal and/or explicitly illegal channels for accessing content.

Although researchers hold their libraries in high regard and understand the motivations behind cancellations, they also still believe that the library's role is to help them access journal content. By extension, any loss of content diminishes the library's role in supporting research. Scholars continue to consider collections and access as the fundamental responsibility of libraries although their reliance on the library to serve these functions is declining. This alters the value proposition that publishers can make to their authors, reviewers, and editors. Scholars who cannot secure access through reviewing, editing or publishing opportunities, due to their career stage and/or the publishing trends in their field, may experience increased structural inequities and diminished access to subscription content. Some libraries and their institutions may be willing to continue to ameliorate those kinds of structural barriers for their researchers whereas others cannot or will not. And, when the library, and by extension, the institution, is less and less directly involved in providing legal channels to accessing content, who bears responsibility for ensuring that researchers are aware of the legal implications behind their choices to pursue various access channels?

Recommendations for navigating the shifting terms of responsibility and value:

- Clarify the library's role in funding open access through article processing charges. The findings in this study suggest that, from the researchers' perspective, library and institutionwide funds have not been an effective at making open access publishing more accessible to authors, warranting further research on this issue and/or exploration of other forms of experimentation. They wonder how the individual actions taken by libraries will lead to new forms of more equitable and sustainable scholarly communication more widely, and they find it challenging to rely on such an unpredictable funding source in the meantime.

- Prepare for the diminishing strategic opportunity that cancelling Big Deals bring to the library in the medium to long-term. In the short term, cancellation may not lead to significant disruption for most researchers, however, when cancellation is approached as a negotiating strategy and not an end point this can be risky, especially when it takes longer to reach a resolution. Cancellation as the end point comes with risks as diminished access changes the terms of the relationship between the university and its researchers.

- Continue to create new and stronger value propositions for researchers. Researchers still equate the library's value with the extent to which it facilitates seamless access to journal content. Researchers remain unclear as to how any particular deal that confers new open access privileges for a set of authors at a specific institution is equivalent to this. Libraries 
also provide a wealth of other resources and services to their users and have the potential to work effectively through collective actions that transcend any individual institution.

However, there is still considerable ground that will need to be made up towards

maintaining the library's value proposition as securing direct access for readers rapidly becomes less of what is on offer.

- Provide clear and ample guidance on appropriate channels for pursuing access beyond institutional subscriptions. Scholars are trying to understand and sort out the changing publishing landscape with different types of open access models and repository types (e.g., institutional repositories, SciHub, academic social networks, document delivery services, interlibrary loan, article rental services, preprint servers, etc.). The confusion over legitimate workarounds continues to lead to uneven practices. 


\section{Appendix A: Partnering Schools and Their Contributors}

Florida State University

Valerie Lynn Boulos, Renaine Julian, Scott Schmucker

Freie Universität Berlin

Michael Dominik Hagel, Franziska Harnisch, Mario Kowalak, Mirco Limpinsel, Cosima Wagner

Ohio University

Janet Hulm

Pennsylvania State University

Lori Cisney, Esther Dell, Mihoko Hosoi, John Meier, Linda Musser, Nonny Schlotzhauer, Kelly

Thormodson, Leigh Tinik

University at Buffalo

Amanda McCormick, Kathleen O'Brien, Erin Rowley

University of Denver

Meg Eastwood, Liam Harty, Jack Maness, Lizbeth South, Zeffie Starling, Shannon Tharp

University of Kansas

Andi Back, Lea Currie, Amalia Monroe-Gulick, Angie Rathmel

University of Oklahoma

Karen Rupp-Serano

University of Pittsburgh

Margarete Bower, Fern Brody, Marnie Hampton, Charlotte Johnson, Marc Ross, Berenika

Webster

University of Wyoming

Kaijsa Calkins, Cass Kvenild, Debbie McCarthy, Lawrence Schmidt

Wesleyan University

Nathan Mealey, Nancy Putnam, Aaron Sandoval 


\section{Appendix B: Packages Included in the Study}

\begin{tabular}{|c|c|c|}
\hline Institution & Package & Status \\
\hline Florida State University & Elsevier & Cancelled in 2019 \\
\hline Freie Universität Berlin & Elsevier & Cancelled in 2018 \\
\hline Ohio University & Elsevier & $\begin{array}{l}\text { Available to researchers at the time } \\
\text { of study }\end{array}$ \\
\hline Pennsylvania State University & Elsevier & $\begin{array}{l}\text { Available to researchers at the time } \\
\text { of study }\end{array}$ \\
\hline University at Buffalo & Elsevier & Cancelled in 2020 \\
\hline University of Denver & Elsevier & $\begin{array}{l}\text { Available to researchers at the time } \\
\text { of study }\end{array}$ \\
\hline University of Kansas & Springer & Cancelled in 2017 \\
\hline University of Oklahoma & Wiley & Cancelled in 2018 \\
\hline University of Pittsburgh & American Institute of Physics & $\begin{array}{l}\text { Available to researchers at the time } \\
\text { of study }\end{array}$ \\
\hline University of Wyoming & Elsevier & $\begin{array}{l}\text { Available to researchers at the time } \\
\text { of study }\end{array}$ \\
\hline Wesleyan University & Elsevier & $\begin{array}{l}\text { Available to researchers at the time } \\
\text { of study }\end{array}$ \\
\hline
\end{tabular}




\section{Appendix C: Interview Sampling Methodology}

We created a sample that is proportionally representative of the total body of transcripts produced across the cohort by institution, departmental affiliation, and rank. This sampling strategy was selected in order to ensure that our analysis represents the collective results of the collection assessment exercise, in which each team systematically selected one to three departments or research concentration areas to target for recruiting based on information about research areas likely affected, or likely to be affected, by a change of access to journal content at their institution. Some departments/research areas were selected for focus by several teams and are therefore represented by a larger number of transcripts, while others were less common. We preserved these proportions in order to accurately represent the likely impacts of past or future contemplated cancellations across the cohort and for consistency we also sampled the two other metadata characteristics (institution and rank) proportionally.

In order to determine the sample, we standardized the metadata regarding department and rank we received from the teams, including by combining some similar or adjacent departments into single categories (e.g. ecology/zoology, e.g. folding postdoctoral researchers from Freie Universität Berlin into the assistant professor category in recognition of how the category functions at that institution). This standardization was necessary to reduce the mathematical complexity of creating a representative sample. We then established target quotas for each institution, departmental affiliation, and rank (by dividing the number of transcripts in a category by the total number of transcripts) and created a sample of 41 transcripts which matched these quotas to within $+/-1$.

\begin{tabular}{lcc}
\hline Rank & Count & Error from Quota \\
\hline Assistant Professor & 11 & 1.11 \\
Associate Professor & 10 & -0.34 \\
Professor & 20 & 0.67 \\
Lecturer & 0 & -0.45 \\
\hline Total & $\mathbf{4 1}$ & $\mathbf{1 . 0 0}$ \\
\hline
\end{tabular}




\begin{tabular}{lcc}
\hline Department & Count & Error from Quota \\
\hline Anthropology & 2 & -0.70 \\
\hline Biology & 5 & 0.51 \\
\hline Biomedical Sciences & 4 & 0.40 \\
\hline Chemistry/Biochemistry & 8 & -0.09 \\
\hline Ecology/Zoology & 3 & 0.30 \\
\hline Engineering & 4 & -0.49 \\
\hline Geoscience & 5 & 0.96 \\
\hline Molecular Biology & 3 & 0.30 \\
\hline $\begin{array}{l}\text { Psychology/Neuroscience/Behavioral } \\
\text { Sciences }\end{array}$ & 7 & -0.19 \\
\hline Total & $\mathbf{4 1}$ & $\mathbf{1 . 0 0}$ \\
\hline
\end{tabular}




\section{Appendix D: Interview Guides}

\section{Interview Guide: Inquiring prior to a change to journal access}

\section{Introduction}

The availability of alternative mechanisms for accessing scholarly content and expectations around financial stewardship is growing. Within this context, the library is conducting a study to understand the best strategies for managing subscriptions. I'd like to ask you questions about the way you access scholarly articles, as well as your views on open access publishing models and the role of the library more broadly.

\section{Discovery and Access Process}

To begin, I'd like to focus on your use of academic journal articles.

1. How do you identify articles to use for your research or teaching? Examples: citations in articles, Google Scholar, Web of Science

- Walk me through your processes of finding and accessing the article step by step. Do your processes vary depending on your goals for searching (e.g. keeping up with the literature vs. conducting a formal literature review)?

- How does your process of finding and accessing articles relate to common practices in your field?

Now I'd like you to think about a time when you identified an article you wanted to look at but found that [name of institution] doesn't subscribe to the journal ("hit a paywall").

2. Can you think of a specific example when this happened?

- Did you continue to look for the article elsewhere?

- If yes, How? Examples: look on ResearchGate, submit an ILL request, email the author or a colleague

- Are there any other strategies you have used in the past to find articles you wanted but couldn't get access to?

- If no Have there been other times when you have continued to look for an article after realizing that you don't have institutional access? Continue with the prompts following If yes

3. What factors influence your decision on how to proceed when you don't have institutional access to an article? Examples: time constraints, availability of other content, reason for using the article

4. Do you have any perspectives on the use of sites like SciHub?

5. Thinking about the times when you can't access articles you're interested in overall, what impact, if any, does this have on your research and teaching? 
- I know that others (like grad students) may be tasked with conducting literature reviews to support faculty-led research projects. What impact, if any, does a lack of institutional access to certain journals have on the work of your students in this capacity?

- What impact, if any, does a lack of institutional access to certain journals have on the work of your students in other capacities? Examples: your ability to assign course readings, students' ability to conduct independent research for class assignments

6. Are there any other issues or thoughts about accessing scholarly articles that you would like to raise?

\section{Other Access Mechanisms}

Next I'd like to get your thoughts on some alternative models for publication and access.

"Preprints" are versions of academic articles before they have gone through formal peer review and publication. Some researchers make preprints of their work available through online repositories, such as their institutional repository, or websites like ResearchGate [if appropriate, add an example in the interviewee's field such as ChemRxiv, arXiv, bioRxiv].

7. Do you use preprints in your research or teaching?

- Would you consider a preprint an acceptable substitute for the published version of an article if the published version isn't available? Why/why not?

- Has your use of preprints increased in the past three years?

8. Another way in which articles can be available without a subscription is if the article is open access. As interest grows around making content openly available there is serious debate about the best models for how those efforts can be sustained financially. Some of the current models include:

- Researchers paying article processing charges (APCs) to make their articles open access, usually out of grant funding or from university-provided funds

- Libraries negotiating paying APCs for the whole institution in bulk

- Institutions investing in institutional repositories where pre-prints are made available

Do you have any perspectives on which, if any, of these models is preferable?

9. Have you reflected on how the ability of other scholars to read your work without a subscription might impact how it is used and cited?

- If so, how does this play into your decision making process when deciding where or how to publish your research? E.g. choosing to publish in open access journals, depositing the non-version of record into an institutional repository

10. Are there any other issues or thoughts about the sustainability of publishing models, preprints, or open access that you'd like to raise? 


\section{The Library's Role}

At our institution and other institutions, a large amount of the library's budget goes toward subscribing to scholarly journals. It can be difficult for libraries to balance out providing content and fiscal responsibility. The growth of open access helps redistribute this balance but there are still many challenges. I'd like to ask you a few questions about the library's role.

11. If a larger share of the scholarly journals you use were no longer available through a library subscription, would this affect your perception of the library? If so, how?

12. Do you anticipate that declining availability of journals by subscription would affect the reputation of your department within your field, or of [institution] more broadly?

13. In the past few years, several universities have chosen to cancel large journal subscription packages. For example, last year the University of California system ended its agreement with Elsevier, which means that their scholars do not have access to new content available via ScienceDirect.

- Are you aware of these or similar kinds of changes at other universities?

- Do you have any perspectives on these universities' actions or their strategies?

14. If the library decides to consider canceling its subscription to journals that are relevant to your work in the future, how would you prefer to receive communication about the possible cancellation?

- What would be the best way for the library to gather input from you or your department?

15. Is there anything else that is important for me to know regarding the role of the library or the other topics we've discussed? 


\section{Interview Guide: Inquiring after a change to journal access}

\section{Introduction}

The availability of alternative mechanisms for accessing scholarly content and expectations around financial stewardship is growing. Within this context, the library is conducting a study to understand the best strategies for managing subscriptions. I'd like to ask you questions about the way you access scholarly articles, as well as your views on open access publishing models and the role of the library more broadly.

\section{Discovery and Access Process}

To begin, I'd like to focus on your own use of academic journal articles.

1. How do you identify articles to use for your research or teaching? (Examples: citations in articles, Google Scholar, Web of Science)

- Walk me through your process of finding and accessing the article step by step. Do your processes vary depending on your goals for searching (e.g. keeping up with the literature vs. conducting a formal literature review)?

- How does your process of finding and accessing articles relate to common practices in your discipline?

2. Now I'd like you to think about a time when you identified an article you wanted to look at but found that [name of institution] doesn't subscribe to the journal ("hit a paywall").

3. Did you continue to try to obtain the article elsewhere?

- If yes, How? (Examples: look on ResearchGate, submit an ILL request, email the author or a colleague)

- Are there any other strategies you have used in the past to find articles you wanted but couldn't get access to?

- If no Have there been other times when you have continued to look for an article after realizing that you don't have institutional access? (Continue with the prompts following If yes)

4. What factors influence your decision on how to proceed when you don't have institutional access to an article?

5. Do you have any perspectives on the use of sites like SciHub?

6. Have you noticed any changes to what journal content is available through the library in the last three years?

7. Are there any other issues or thoughts about accessing scholarly articles more broadly that you would like to raise?

\section{Other Access Mechanisms}

Next I'd like to get your thoughts on some alternative models for publication and access. 
"Preprints" are versions of academic articles before they have gone through formal peer review and publication. Some researchers make preprints of their work available through online repositories, such as their institutional repository, or websites like ResearchGate [if appropriate, add an example in the interviewee's field such as ChemRxiv, arXiv, bioRxiv].

8. Do you use preprints in your research or teaching?

- Would you consider a preprint an acceptable substitute for the published version of an article if the published version isn't available? Why/why not?

- Has your use of preprints increased in the past three years?

9. Another way in which articles can be available without a subscription is if the article is open access. As interest grows around making content openly available there is serious debate about the best models for how those efforts can be sustained financially. Some of the current models include:

- Researchers paying article processing charges (APCs) to make their articles open access, usually out of grant funding or from university-provided funds

- Libraries negotiating paying APCs for the whole institution in bulk

- Institutions investing in institutional repositories where pre-prints are made available

Do you have any perspectives on which, if any, of these models is preferable?

10. Have you reflected on how the ability of other scholars to read your work without a subscription might impact how it is used and cited?

- If so, how does this play into your decision making process when deciding where or how to publish your research? Examples: choosing to publish in open access journals, depositing the non-version of record into an institutional repository

11. Are there any other issues or thoughts about the sustainability of publishing models, preprints, or open access that you'd like to raise?

\section{About the Cancellation}

In [month, year], the library canceled its subscriptions to a number of [publisher] titles, including [insert a few that are associated with this person's department]. Issues published before [month, year] are still available through our institution, but any issues published since then aren't.

12. Were you aware of this cancellation?

- How did you find out about it?

- Do you feel you understand the library's rationale for canceling these titles?

- Given that you still have access to articles published before [month, year], can you explain at which point this archive will be too out of date to still be useful to your research?

13. Has this cancellation affected your or your colleagues' research or teaching? How? 
- I know that others (e.g. grad students) may be tasked with conducting literature reviews to support faculty-led research projects. What impact, if any, has this cancellation had on the work of your students in this capacity?

- What impact, if any, does a lack of institutional access to certain journals have on the work of your students in other capacities? Examples: your ability to assign course readings, students' ability to conduct independent research for class assignments

- Has the cancellation affected the reputation of your department within your field, or of [institution] more broadly? If so, how?

14. Has the cancellation affected your perception of the library? If so, how?

15. In the past few years, several universities have chosen to cancel large journal subscription packages. For example, last year the University of California system ended its agreement with Elsevier, which means that their scholars do not have access to new content available via ScienceDirect.

- Are you aware of these or similar kinds of changes at other universities?

- Do you have any perspectives on these universities' actions or their strategies?

16. Is there anything else that is important for me to know regarding the cancellation, the role of the library or the other topics we've discussed? 